\title{
USING SOLAR PV INVERTERS AT NIGHT FOR VOLTAGE STABILIZATION: A Case Study
}

\author{
A. S. Rodrigo ${ }^{1}$ \& K. K. Navoda ${ }^{2}$ \\ ${ }^{1}$ Senior Lecturer, Department of Electrical Engineering, University of Moratuwa \\ ${ }^{2}$ Electrical Engineer, Ceylon Electricity Board
}

\begin{abstract}
Installation of grid-connected rooftop solar power generation modules has been allowed in Sri Lanka since 2008. The paper analyzes the potential use of solar power inverters at night to feed reactive power to the low voltage (LV) network. The LV network typically has undervoltage issues at the evening peak-time, and the PV inverters distributed along the line can be used to eliminate or reduce such undervoltage issues. The paper proposes an algorithm to determine the suitable operating power factor of each inverter connected to the feeder. A case study of a LV distributor with solar PV inverters is presented, to demonstrate the application of the algorithm. Financial benefits to customer by introducing a reactive power tariff is assessed. The paper concludes that such a system would yield net benefits to the utility.
\end{abstract}

\section{Key Words}

Power factor, PV inverter, reactive power

\section{Introduction}

Electricity production from rooftop solar PV systems is rapidly increasing in Sri Lanka. By end 2017, about 100 MW of rooftop solar PV systems were in operation. The annual capacity factor of solar PV installations is limited to about $17 \%$ owing to several reasons including the dependence of solar power generation on the availability of irradiation. This means, the inverter installed to convert the dc output of solar PV to ac to feed the utility LV network, largely remains underutilized most of the time. During the night-peak when the solar PV generation is negligible, the inverter remains shutdown.

Kozinda, Beach and Rao [1] demonstrated a number of opportunities to use the potential of inverters for a variety of power system applications.

Under voltage issues occur along distribution lines, partly owing to reactive power required by customers' end-use appliances. Solar PV inverters could be considered as distributed VAR injectors. In late evening when typically, both real and reactive power flows on LV lines are at their maximum, active power generation on each solar module is zero. Therefore, PV inverters may be used during that period to feed reactive power to the system. Operating power factor for each inverter may be decided by the utility, based on measured feeder loading and the calculated voltage profile. This concept has not yet been implemented in Sri Lanka.

If implemented, the strategy involves the utilization of the PV inverter which is a customer's property, for the improvement of the utility's LV system. To encourage customers to participate, a reward scheme may be introduced.

This requires a tariff for reactive power to be introduced in Sri Lanka. Currently, the maximum demand charge for bulk customers is the only indirect charge for reactive power drawn by customers from the grid. The purpose of introducing the maximum demand charge was to encourage customers to manage their demand, and thereby, minimize line currents and voltage drops in the utility network.

\section{General Algorithm}

A general algorithm was developed to identify line segments and the inverters selected to serve reactive power, and the output power setting of inverters. The description below is for a typical overhead LV radial distribution line in Sri Lanka. (i) Based on the calculated voltage profile along the feeder, a zone with under voltage would be identified, to confirm that an undervoltage problem exists. (ii) Then the real power loss would be calculated for each line segment with the highest real power loss would be identified, (iii) if customers served by the end-pole of the identified line segment have inverters installed, then the desired power factor would be set on such inverters. (iv) the voltage profile would be re-calculated, assuming the inverters now inject 
the desired amount of reactive power, (v) If the calculated voltage at the pole is higher than the limit then increase the power factor and repeat the steps. (vi) If an inverter was not connected at the selected pole then check for the nearest installed inverter and set the power factor. (vii) The same procedure would be repeated until the under-voltage issue is eliminated or minimized along the distribution line.

The calculated power factor could be conveyed to the respective customers and requested to set and operate their inverters at the peak time.

\section{Case Study}

Parameters of the sample feeder are shown in Table 1. The $1.5 \mathrm{~km}$ long sample feeder is in the western province of Sri Lanka, and has 15 solar PV systems installed along the feeder

\section{Table 1- Parameters of the Sample Feeder}

\begin{tabular}{|c|c|c|c|c|}
\hline $\begin{array}{l}\text { Length } \\
\text { along } \\
\text { the } \\
\text { feeder } \\
(\mathrm{m})\end{array}$ & $\begin{array}{l}\text { Number of } \\
\text { service } \\
\text { connection } \\
\text { s at the } \\
\text { pole } \\
\text { (node) }\end{array}$ & $\begin{array}{c}\text { Installed } \\
\text { inverter } \\
\text { capacity } \\
(\mathrm{kVA})\end{array}$ & $\begin{array}{c}\text { Active } \\
\text { power } \\
\text { load } \\
\text { off the } \\
\text { node } \\
(\mathrm{kW})\end{array}$ & $\begin{array}{c}\text { Reactiv } \\
\text { e power } \\
\text { load off } \\
\text { the } \\
\text { node } \\
\text { (kVAr) }\end{array}$ \\
\hline \multicolumn{5}{|c|}{, } \\
\hline 40 & 2 & 0.5 & 1.20 & 0.60 \\
\hline 80 & 2 & & 1.30 & 0.60 \\
\hline 120 & 1 & & 0.56 & 0.40 \\
\hline 160 & 2 & 1 & 1.50 & 0.60 \\
\hline 200 & 2 & & 0.92 & 0.51 \\
\hline 240 & 3 & & 1.36 & 0.94 \\
\hline 280 & 1 & 2 & 1.11 & 0.73 \\
\hline 320 & 2 & & 0.75 & 0.44 \\
\hline 360 & 2 & & 0.64 & 0.18 \\
\hline 400 & 2 & & 0.45 & 0.25 \\
\hline 440 & 3 & 3 & 1.28 & 0.30 \\
\hline 480 & 2 & & 1.33 & 0.61 \\
\hline 520 & 1 & & 0.95 & 0.70 \\
\hline 560 & 1 & 0.5 & 0.64 & 0.37 \\
\hline 600 & 2 & & 1.20 & 0.50 \\
\hline 640 & 3 & 1.5 & 1.37 & 0.14 \\
\hline 680 & 1 & & 0.94 & 0.27 \\
\hline 720 & 3 & 0.5 & 2.20 & 1.20 \\
\hline 760 & 2 & & 1.06 & 0.52 \\
\hline 800 & 1 & 2 & 1.12 & 0.60 \\
\hline 840 & 2 & 0.5 & 1.23 & 0.47 \\
\hline 880 & 1 & & 0.86 & 0.70 \\
\hline 920 & 1 & & 0.81 & 0.50 \\
\hline 960 & 2 & 2 & 1.80 & 0.62 \\
\hline 1000 & 3 & & 2.21 & 0.72 \\
\hline 1040 & 2 & & 1.25 & 0.76 \\
\hline 1080 & 1 & 0.5 & 0.94 & 0.45 \\
\hline 1120 & 2 & & 1.68 & 0.49 \\
\hline 1160 & 1 & & 0.85 & 0.73 \\
\hline
\end{tabular}

\begin{tabular}{|c|c|c|c|c|}
\hline 1200 & 1 & 1 & 1.20 & 0.35 \\
\hline 1240 & 1 & & 0.76 & 0.27 \\
\hline 1280 & 2 & 3.5 & 0.91 & 0.50 \\
\hline 1320 & 1 & & 0.80 & 0.20 \\
\hline 1360 & 1 & 0.5 & 0.61 & 0.37 \\
\hline 1400 & 1 & 1 & 0.68 & 0.34 \\
\hline 1440 & 2 & & 0.80 & 0.26 \\
\hline 1480 & 1 & & 1.50 & 0.31 \\
\hline 1520 & 1 & & 0.75 & 0.30 \\
\hline Total & 64 & 20 & 41.52 & 18.8 \\
\hline
\end{tabular}

Note: Active and reactive power demand shown in columns 4 and 5 are the peak-time demand of the customer (or cumulative demand of customers) served off the node. Information was obtained from a load research study conducted by CEB in a semi-urban area.

Using the parameters of the feeder and the connected loads and considering the sendingend voltage to be $1 \mathrm{pu}$, a load flow study was conducted using the SynerGEE model. The study revealed that an under-voltage situation would occur at $640 \mathrm{~m}$ along the feeder, at which point the voltage would drop below $0.94 \mathrm{pu}$, the lowest allowed under Sri Lanka's distribution code. The calculated voltage profile is shown in Figure 1.

\section{Figure 1- LV Feeder Voltage Profile without Reactive Power Injection}

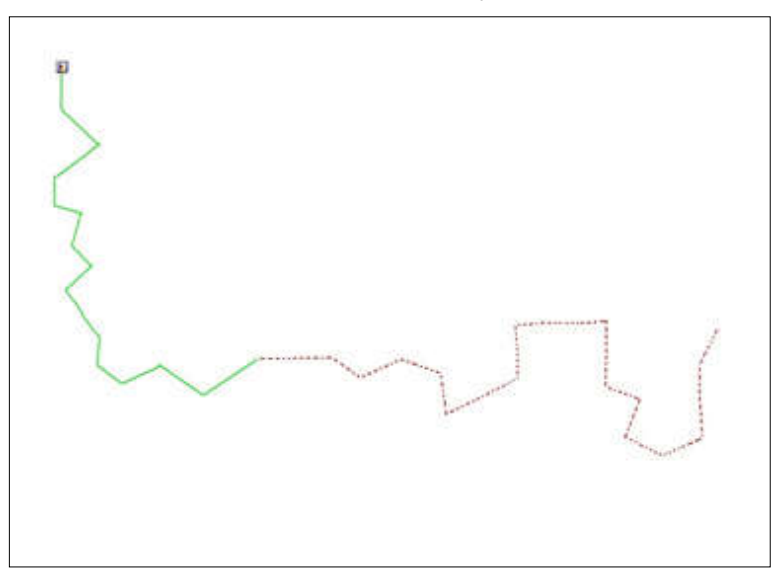

Note: Line segments that violate the lower voltage limit of $0.94 \mathrm{pu}$ are shown in dotted lines.

The algorithm presented earlier was applied, to use inverters to inject reactive power to selected nodes. The final operating power factor of each PV inverter is shown in Table 2.

\section{Table 2 - Computed Operating Power Factor}

\begin{tabular}{|c|c|c|c|}
\hline $\begin{array}{c}\text { Length } \\
\text { along the } \\
\text { feeder }(\mathrm{m})\end{array}$ & $\begin{array}{c}\text { Installed } \\
\text { inverter } \\
\text { capacity } \\
(\mathrm{kVA})\end{array}$ & $\begin{array}{c}\text { Final Power } \\
\text { Factor Setting } \\
\text { on the } \\
\text { Inverter }\end{array}$ & $\begin{array}{c}\text { Reactive } \\
\text { power } \\
\text { injected } \\
\text { (kVAr) }\end{array}$ \\
\hline 40 & 0.5 & - & - \\
\hline
\end{tabular}




\begin{tabular}{|c|c|c|c|}
\hline 160 & 1.0 & 0.80 & 0.60 \\
\hline 280 & 2.0 & 0.93 & 0.74 \\
\hline 440 & 3.0 & 0.99 & 0.42 \\
\hline 560 & 0.5 & 0.67 & 0.37 \\
\hline 640 & 1.5 & 0.99 & 0.21 \\
\hline 720 & 0.5 & - & - \\
\hline 800 & 2.0 & 0.95 & 0.62 \\
\hline 840 & 0.5 & 0.28 & 0.48 \\
\hline 960 & 2.0 & 0.95 & 0.62 \\
\hline 1080 & 0.5 & 0.44 & 0.45 \\
\hline 1200 & 1.0 & 0.94 & 0.34 \\
\hline 1280 & 3.5 & 0.99 & 0.49 \\
\hline 1360 & 0.5 & 0.67 & 0.37 \\
\hline 1400 & 1.0 & 0.94 & 0.34 \\
\hline Total & 20.00 & & 6.07 \\
\hline
\end{tabular}

Note: The power factor setting on the inverter (column 3) is on the basis of rated active power of the inverter (although no active power is delivered by the inverter during the evening peak period). The calculated reactive power injection is given in column 4 .

Inverters were now placed along the feeder with their reactive power factor set according to Table 2. Figures 2 and 3 show the calculated voltage profile along the line.

\section{Figure 2 - LV Feeder Voltage Profile with Reactive Power Injection}

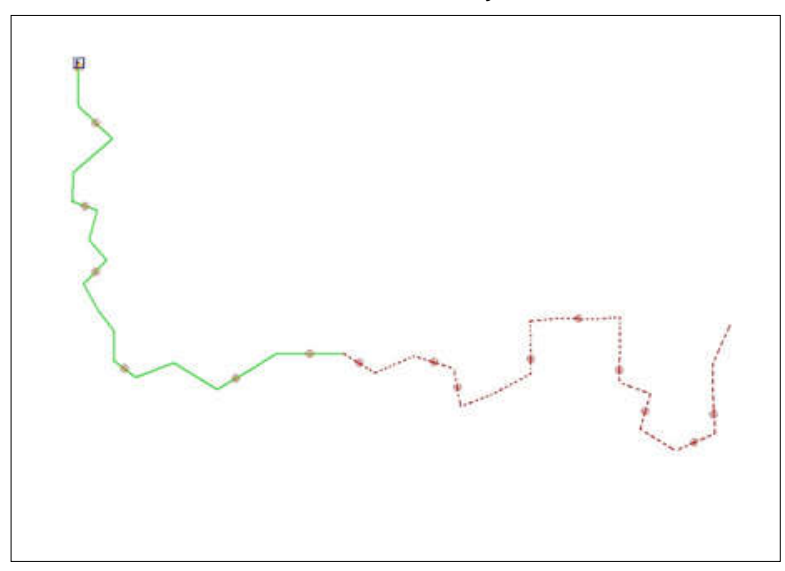

Note: Line segments that violate the lower voltage limit of $0.94 \mathrm{pu}$ are shown in dotted lines. Line segments where inverters are active are marked with a circle.

Figure 3 - LV Feeder Voltage Improvement with Reactive Power Injection

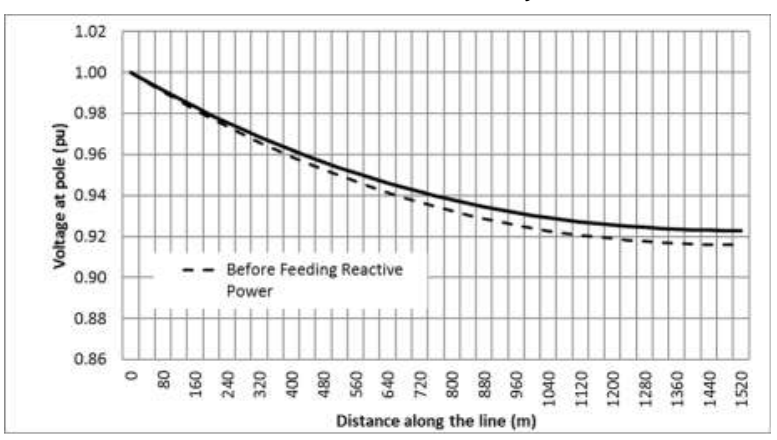

Voltage profiles indicate that in the absence of reactive power infeed, voltage violations occur from $640 \mathrm{~m}$ onwards. Once the reactive power feed-in from inverters was enabled, undervoltage occurs from $720 \mathrm{~m}$ onwards. The points at $640 \mathrm{~m}$ and $680 \mathrm{~m}$ along the feeder were no longer have a voltage issue.

\section{Financial Analysis}

There are two types of financial benefits associated with the initiative to inject reactive power at inverters. (i) reduced energy losses along the feeder, (ii) benefits of released capacity that can be used to serve future customers.

Value of reduced energy losses: In the case study, the power loss before and after reactive power injection was $1.954 \mathrm{~kW}$ and $1.773 \mathrm{~kW}$, respectively. This reduction of power loss was $0.181 \mathrm{~kW}(9.3 \%$ of the base case).

The operating period of inverters in the reactive power injection mode was assumed to be limited to peak hours (ie 4 hours per day) [2]. This assumption aligns with Sri Lanka's time-of-use tariff, in which the peak period is defined to be from 1830 to 2230 (4 hours).

Energy saving was therefore calculated to be, Energy saving $=$ Avoided power loss $\times$ peak hours $\times 365=0.181 \times 4 \times 365=264 \mathrm{kWh} /$ year

The value of energy at peak-time in year 2015 as published in the bulk supply tariff [3] was Rs 11.97 per $\mathrm{kWh}$. This value is for power delivered at transmission voltage to distribution entities.

The calculated energy saving in this study is along LV lines. Losses saved along medium voltage lines and the distribution transformer were estimated to be $1 \%$ and $2 \%$ of input the respective segments [4]. Accordingly, saving of losses along LV lines would reflect as 299 $\mathrm{kWh} /$ year.

Accordingly, the value of energy saved owing to the reduction of loss by inverter operation was estimated to be Rs 3,525 per year.

Benefits of Released Capacity: Increased line capacity owing to reactive power infeed by solar PV inverters was calculated according to reference [5]. The calculated line current without compensation was $91.4 \mathrm{~A}$, which reduced to 
87.0 A with compensation. The released capacity of the line may therefore be estimated to be 3.1 kVA. Sri Lanka's generation and transmission capacity costs have been estimated in [3] to be Rs 2713 per peak-kW, per month. Therefore, assuming a power factor 0.8 , the value of upstream capacity saved was estimated to be Rs 6728 per month (or Rs 80,738 per year). The value of capacity saved in distribution transformers and the MV distribution network would be small, and was therefore neglected.

Accordingly, the total financial savings to the utility is estimated to be Rs 3,525+Rs 80,738 = Rs 84,264 per year. Assuming a discount rates of $20 \%$, and assuming all costs remain the same in real terms, the present value of savings to the utility is estimated to be Rs 241,456 for a 5-year period.

\section{Rewards to Customers}

A reactive power tariff needs to be determined to compensate customers for their participation in compensation. For determination of the reactive tariff for consumption the Case Study results calculation was computed when a capacitor banks fixed at customer end. The assumptions made are given in Table 3 .

Table 3 - Assumptions to derive a Tariff for Reactive Power Injection

\begin{tabular}{|l|c|}
\hline $\begin{array}{l}\text { Life time of a capacitor } \\
\text { bank }\end{array}$ & 5 years \\
\hline $\begin{array}{l}\text { Annual maintenance cost } \\
\text { (\% of capital cost) }\end{array}$ & $2 \%$ \\
\hline Capital cost & Rs 3000 per kVAr \\
\hline Discount rate & $20 \%$ \\
\hline
\end{tabular}

Considering the pole at $160 \mathrm{~m}$ away from the transformer, the reactive power injection required was $0.6 \mathrm{kVAr}$. Assume that $1 \mathrm{kVAr}$ capacitor bank was installed (which also matches with the rating of the inverter). The capacitor bank operates at the peak time, flor 4 hours per day.

Total reactive energy injected by the customer $=0.6 \times 4 \times 365=876 \mathrm{kVArh}$

If $\mathrm{T}$ (Rs/kVArh) is the tariff for reactive energy paid to a customer,

$T \sum_{i=1}^{5} \frac{876}{(1+0.2)^{i}}-3000+\sum_{i=1}^{5} \frac{60}{(1+0.2)^{i}}$
$\mathrm{T}=1.01 \mathrm{Rs} / \mathrm{kVArh}$

The case study LV feeder has a total of $20 \mathrm{kVA}$ of inverters, of which $19 \mathrm{kVA}$ would be used for reactive power injection. Assuming that a cumulative capacity of $19 \mathrm{kVAr}$ of capacitors were installed by customers, the cumulative injection of reactive power will be 6.07 kVAr.(see Table 2). The calculated levelized cost was $1.90 \mathrm{Rs} / \mathrm{kVArh}$, for customers to recover their costs without a financial loss.

Therefore, this study proposes a tariff of 2.00 Rs/kVArh for customers injective reactive power to the system at LV feeder level.

Present value of payments to customers at 2.00 Rs $/$ kVArh = Rs 52,975

Present value of benefits to utility $=$ Rs 241,456

Benefit to cost ratio $=4.6$

\section{Conclusion}

Solar PV inverters distributed along the feeder even of smaller capacities can be used to reduce the under voltage along LV feeders at peak time.

The proposed tariff for reactive power injection associated with solar PV inverters is 2.00 Rs/kVArh. Further studies are proposed to reevaluate the upstream capacity benefits in the longer term of reactive power injection at LV, through system-level modelling.

\section{References}

[1] A. Kozinda, T. Beach, V. Rao, "Latent Opportunities for Localized Reactive Power Compensation," Cal $x$ Clean Coalition Energy C226, 2013.

[2] Statistical Digest 2015, Ceylon Electricity Board, Sri Lanka.

[3] "Decision on Bulk Supply and Transmission Tariffs, effective from $1^{\text {st }}$ July 2015", Public Utilities Commission of Sri Lanka, 2015.

[4] Resource Management Associates (Pvt) Ltd, "A Tariff for Reactive Power in Sri Lanka", Final Report, September 2011.

[5] N. Kutkut, "An ac PV Module with Reactive Power Capability: Need and Benefit," Petra Solar, Inc., 2012.

\section{Additional References}

[6] Ceylon Electricity Board, "Manual for Interconnection of Micro Scale Renewable Energy Based Power Generating Facilities at 
Low Voltage Consumer Feeders of National Grid", August 2016.

[7] SMA Solar Technology, America "Q at Night," Reactive power outside of feed-in operation with SUNNY CENTRAL 500CP XT / 630CP XT / 720CP XT /760CP XT / 800CP XT / 850CP XT / 900CP XT".
[8] Inverter Reactive Power Compensation (2014):

http:/ / www.blueoakenergy.com/blog/inve rter-reactive-power, Visited, 24 ${ }^{\text {th }}$ November 2016. 